\title{
Reflexiones acerca de la aplicación de la nueva normativa sobre transparencia pública
}

\author{
Emilio Guichot
}

Catedrático acreditado de Derecho Administrativo

Universidad de Sevilla

SUMARIO: I. PRIMERA HIPÓTESIS: UNA LEY DE TRANSPARENCIA ES UN INSTRUMENTO ÚTIL PARA LA PREVENCIÓN DE LA GORRUPCIÓN Y LA MEJORA DEL GOBIERNO, PERO NO BASTA SIN MECANISMOS EFEGTIVOS DE APLICAGIÓN, VOLUNTAD DE PONERLOS EN FUNGIONAMIENTO Y UNA CIUDADANÍA ACTIVA QUE EJERZA Y BATALLE POR SU DERECHO A SABER. II. SEGUNDA HIPÓTESIS: LA TRANSPARENCIA HA SIDO UNA PRIORIDAD FIJADA DE ABAJO ARRIBA AL CALOR DE CASOS DE CORRUPCIÓN QUE HAN PRODUCIDO UNA DESCONFIANZA RADICAL EN LA POLÍTICA Y EN LAS INSTITUCIONES. III. TERGERA HIPÓTESIS: LA LEY ESPAÑOLA Y LA MAYOR PARTE DE LAS LEYES AUTONÓMICAS SE SITÚAN EN UN RANGO RAZONABLE DE EXIGENCIA, PERO DEJA UN AMPLIO MARGEN DE DESARROLLO NORMATIVO Y DE INTERPRETAGIÓN APLICATIVA DE CUYO USO DEPENDERÁ EL NIVEL REAL DE TRANSPARENCIA. IV. GUARTA HIPÓTESIS: SIN AUTORIDADES DE CONTROL INDEPENDIENTES DE DERECHO Y DE HECHO NO HABRÁ AUTÉNTICA TRANSPARENGIA.

\section{RESUMEN}

En el trabajo se lleva a cabo una aproximación global a la nueva regulación estatal y autonómica de la transparencia: sentido, origen, contenido y garantías. Se insiste en la necesidad de analizar no sólo su profundidad o calidad sino también el papel decisivo que, a la vista del carácter abstracto de muchos de sus conceptos claves, corresponde al intérprete y aplicador, y en especial, a las autoridades de control. Sólo esa visión conjunta de contexto, texto y aplicación ofrece la medida del nivel real de transparencia pública en el que nos situamos. 


\section{PALABRAS CLAVES}

Transparencia. Acceso a la información pública Autoridades de transparencia

\section{ABSTRACT}

In this article a global approach to the new state and regional regulation of transparency is carried out: meaning, origin, content and guarantees. It insists on the need to analyze not only the depth or quality of the legal provisions but also the decisive role of the interpreter and applicator, and in particular to the supervisory authorities, in view of the abstract nature of many of its key concepts. Only this joint vision of context, text and application provides the measure of the actual level of public transparency.

\section{KEY WORDS}

Transparency. Access to public information. Transparency supervisory authorities

\section{PRIMERA HIPÓTESIS: UNA LEY DE TRANSPARENCIA ES UN INSTRUMENTO ÚTIL PARA LA PREVENCIÓN DE LA GORRUPGIÓN Y LA MEJORA DEL GOBIERNO, PERO NO BASTA SIN MEGANISMOS EFEGTIVOS DE APLICACIÓN, VOLUNTAD DE PONERLOS EN FUNGIONAMIENTO Y UNA GIUDADANÍA ACTIVA QUE EJERZA Y BATALLE POR SU DEREGHO A SABER}

La transparencia, auténtico mantra, palabra mágica en el actual lenguaje político, es un instrumento clave para el control de la gestión pública, entendido en sus perspectivas preventiva y represora, y por ende, para su mejora.

Dos referencias a dos juristas y transformadores sociales por los que profeso una profunda admiración pueden dar cuenta de las virtudes de la transparencia.

La primera se refiere a Louis Dembitz Brandeis y a su celebérrima frase "se dice que la luz del sol es el mejor de los desinfectantes", que se ha convertido en la imagen más conocida que asocia transparencia y lucha contra la corrupción ${ }^{1}$.

\footnotetext{
${ }^{1}$ En 1914, en su libro Other People's Money, and how the Bankers use it. No es casual que fuera Louis Dembitz Brandeis su autor. Alumno excepcional de la Facultad de Derecho de Harvard, abogado y, desde 1916, juez del Tribunal Supremo de los Estados Unidos de América hasta su jubilación, dos años antes de su muerte en 1941. Destacó, como estudioso, como abogado y como juez, en la defensa militante de la libertad de expresión y el derecho a la intimidad, siendo de hecho el que formuló el concepto de "derecho a la intimidad" a nivel mundial, en su célebre trabajo "the right to privacy", publicado en 1890 en la Harvard Law Review junto a su colega Samuel Warren, y posteriormente incorporado en 1928 a su voto particular en la
} 
La segunda a Barack Obama, que un siglo más tarde, y citando esta misma frase de Louis Dembitz Brandeis, convirtió la apuesta por la transparencia y la rendición de cuentas, en un contexto de mejora hacia una Administración abierta a la participación ciudadana, en uno de los ejes de su acción política, hasta el punto de dedicarle simbólicamente el primer acto de gobierno del primer mandato².

En España estamos en un momento "fundacional" de la transparencia desde el punto de vista jurídico. A finales de 2013 se aprobó la Ley 19/2013, de 9 de noviembre, de Transparencia, Acceso a la Información Pública y Buen Gobierno (en adelante, LT), la primera regulación legal integral sobre la materia en España. Durante su larga tramitación se pusieron de relieve las grandes expectativas depositadas por la sociedad en esta norma como instrumento de regeneración democrática y, en particular, como instrumento de lucha contra la corrupción. Una ley esperada, al menos, desde 1978, en que la Constitución Española en su artículo 105.b llamó a la aprobación de una ley para regular "el acceso de los ciudadanos a los archivos y registros administrativos, salvo en lo que afecte a la seguridad y defensa del Estado, la averiguación de los delitos y la intimidad de las personas".

Hemos llegado, en fin, en retaguardia a la aprobación de una Ley de Transparencia. Como he desarrollado en otros escritos, los países pioneros en el reconocimiento y regulación del derecho de acceso a la información pública se encuentran entre los más desarrollados del mundo desde una perspectiva democrática, social y económica. En efecto, el movimiento comenzó como una brisa (fría, por su proveniencia) que se levantó en los países escandinavos y recorrió el Atlántico para recalar en los Estados Unidos, Canadá y los países de su área de influencia. La brisa se convirtió en un viento

Sentencia del Tribunal Supremo Olmstead v. Estados Unidos. Toda su trayectoria profesional estuvo marcada por la lucha por la justicia social y contra la concentración, la opacidad y la corrupción del poder político y económico (lo que le valió el sobrenombre "abogado de la gente" en su etapa de abogado pro bono). Fue, además, el introductor de la técnica del acompañamiento de los escritos jurídicos con estudios y peritajes extrajurídicos, fiel reflejo de su apuesta por la interpretación del Derecho a la luz del sustrato sociológico y económico.

2 Barack Obama, también brillante estudiante de la Facultad de Derecho de Harvard y presidente de la Harvard Law Review y posteriormente activista social y abogado de derechos civiles y profesor de la Universidad de Chicago, Presidente de los Estados Unidos de América y Premio Nobel de la Paz. Realizó una importantísima apuesta por la transparencia desde el comienzo de su trayectoria política. Ya lo hizo como senador, con la aprobación el 26 de septiembre de 2006, de la Federal funding accountability and transparency act, conocida como la Coburn-Obama bill (por ser el resultado del impulso de estos dos senadores) o, más popularmente, como Google for government, encaminada a dar transparencia a los gastos públicos y a todos los contratos públicos. Posteriormente, como Presidente, su primer acto de Gobierno al día siguiente de su toma de posesión, consistió en la aprobación de dos Memoranda relativos a la aplicación de la Freedom of Information Act (FOIA) y a la idea de Gobierno abierto, en el que apuesta por la transparencia y la interpretación más amplia de la normativa sobre acceso a la información como claves de un gobierno abierto, colaborativo, participativo y eficaz. 
entre finales de los setenta y principios de los noventa, en que se expandió entre los países latinos de la Europa occidental. Y, finalmente, se transformó en un huracán, pues a finales de los noventa y principios del siglo XXI se produjo una generalización de la aprobación de leyes de transparencia y acceso a la información pública en los países de Europa occidental que aún carecían de ella (Reino Unido, Alemania, Suiza); en los países de Europa del Este y de Latinoamérica y, en fin, en países de Asia, África y Oceanía. En muchos de estos casos, vino acompañando al tránsito de regímenes no democráticos, en que el individuo era transparente y el poder opaco, a regímenes democráticos en que la situación se invirtió. El fenómeno se hizo, así, mundial, hasta el punto de que existen ya instrumentos regionales como, en Europa, el Convenio núm. 205 del Consejo de Europa sobre acceso a los documentos públicos (CEADP), abierto a la firma de los Estados el 18 de junio de 2009, que establece un mínimo estándar europeo, o, en América, la Ley Modelo Interamericana Interamericana sobre derecho de acceso a la información, aprobada por la Asamblea General de la Organización de los Estados Americanos en 2010. En definitiva, el derecho de acceder a la información pública es una conquista que sólo se ha globalizado como consecuencia de la cuasi generalización del sistema de democracia representativa y de la lucha en su seno por una profundización en los mecanismos de control democrático ${ }^{3}$.

Resulta del máximo interés constatar que los países que han llegado antes a la transparencia coinciden con aquellos cuya ciudadanía perciben un menor grado de corrupción en el funcionamiento de sus gobiernos, de acuerdo con el Índice de Percepción de la Corrupción elaborado año tras año por la ONG Transparencia Internacional por el método de plantear las mismas cuestiones a ciudadanos de 177 países del mundo. No se quiere decir con ello que haya una relación causal exclusiva y directa entre normativa de transparencia y cuasi erradicación de la corrupción, sino, más bien, que se da un "círculo virtuoso": los países más desarrollados democráticamente llegaron primero a aprobar normas sobre transparencia porque estaban preparados para esa apuesta (signo de que eran, por ende, menos tolerantes a la corrupción pública) y su puesta en práctica ha contribuido a prevenir prácticas corruptas institucionales o generalizadas.

Ahora bien, los estudios y el sentido común también nos advierten de que no basta con tener una buena Ley. Si acudimos al último estudio internacional sobre calidad de las Leyes estatales de transparencia de más de cien países ${ }^{4}$, nos encontraremos con el dato de que entre las diez mejor valoradas se encuentran, por ejemplo, las de Libe-

${ }^{3}$ Con detalle sobre la cronología, véase, entre otros, GUICHOT, E., "Derecho de acceso a la información: experiencias regionales y estatales en Europa y América", Derecho Comparado de la Información, enero-junio 2012, pp. 135-188.

${ }^{4}$ http://www.rti-rating.org/ 
ria, El Salvador o Sierra Leona, y entre las peor valoradas, las de Alemania, Austria, Bélgica o Italia ${ }^{5}$. Cabe cuanto menos dudar de que la práctica de la transparencia por la Administración (qué información se pone a disposición de todos en Internet y si es verdadera y actualizada, cuál es el tiempo real de respuesta a las solicitudes, en cuántos casos la respuesta de la Administración consiste en la inactividad o en afirmar que no dispone de la información, si se destinan suficientes recursos humanos cualificados a la aplicación de las leyes de transparencia, si hay o no una autoridad realmente independiente de garantía, si su independencia es real y cómo funciona...) sea acorde con estas valoraciones de la estructura normativa. A ello habría que sumar un estudio sobre el uso real que los ciudadanos hacen de este derecho y de la práctica de los tribunales al conocer de las demandas de acceso, allí donde hay tribunales independientes y con costes de tiempo y dinero no disuasorios.

En fin, como decía, mi primera hipótesis es que una ley de transparencia es un instrumento útil para la prevención de la corrupción y la mejora del gobierno, pero no basta sin mecanismos efectivos de aplicación, voluntad de ponerlos en funcionamiento y una ciudadanía activa que ejerza y batalle por su derecho a saber.

\section{SEGUNDA HIPÓTESIS: LA TRANSPARENGIA HA SIDO UNA PRIORIDAD FIJADA DE ABAJO ARRIBA AL CALOR DE CASOS DE GORRUPGIÓN QUE HAN PRODUCIDO UNA DESCONFIANZA RADICAL EN LA POLÍTICA Y EN LAS INSTITUGIONES}

En España, como decía, estamos asistiendo en estos años a un momento "fundacional". Los impulsos de la sociedad (ciudadanos en general, organizaciones no gubernamentales, periodistas, académicos) en tiempos de una profunda crisis de confianza política, institucional y económica han colocado la transparencia en la agenda política de forma no sólo nominal sino efectiva, de forma muy notoria a partir del año 2011, en que, fruto de esos impulsos, la aprobación de una Ley de Transparencia figuró ya en todos los programas políticos de los partidos de ámbito nacional que obtuvieron representación parlamentaria, asociada al debate sobre la corrupción y la necesidad de una regeneración democrática. Tras una larga tramitación derivada sobre todo de la comparecencia de expertos en el Congreso de los Diputados, acompañada de

${ }^{5}$ En concreto, las diez primeras son, en este orden, las de Serbia, Eslovenia, India, Croacia, Liberia, El Salvador, Sierra Leona, Sudán del Sur, México y Maldivas, y en el furgón de cola se encuentran Austria, Liechtenstein, Tajikistan, Alemania, Jordania, Italia, Taiwan, República Dominicana, Bélgica y Uzbekistan. 
un intenso debate ciudadano ${ }^{6}$, mediático ${ }^{7}$ y académico $^{8}$, se aprobó, con importantes modificaciones en la ampliación de los sujetos obligados y en la institución independiente de garantía respecto de lo previsto en el proyecto de Ley, la Ley 19/2013, de 9 de diciembre, de transparencia, acceso a la información pública y buen gobierno ${ }^{9}$. Durante su larga tramitación ${ }^{10}$ y tras su aprobación ${ }^{11}$ se pusieron de relieve las grandes

${ }^{6} \mathrm{El}$ Anteproyecto se sometió a un novedoso procedimiento de consulta pública entre los días 26 de marzo y 10 de abril.

${ }^{7}$ Por todos, entre los artículos de expertos en la materia, A. GARRIGUES WALKER, J. LIZCANO ÁLVAREZ, J. SÁNCHEZ LAMBÁS y M. VILLORIA MENDIETA (integrantes del Comité de Dirección de Transparencia Internacional España) en el diario EL PAIS, bajo el título "La Ley de Transparencia, solo el primer paso", el 5 de abril de 2012 (http://elpais.com/elpais/2012/03/29/opinion/1333034562 798871. html), o E. GUICHOT, en el diario ABC, con el título "Transparencia: la hora de la verdad", el 30 de abril de 2012 (http://www.abc.es/historico-opinion/index.asp?ff=20120430\&idn=1502732850340), y "Luces y sombras de la Ley de Transparencia", diario EL PAÍS, 5 de julio de 2013 (http://elpais.com/ elpais/2013/06/26/opinion/1372261737_042333.html).

8 Vid. GUICHOT, E., "El Anteproyecto de Ley de Transparencia", El Cronista del Estado Social y Democrático de Derecho, núm. 30, junio 2012, pp. 28-40, y "El proyecto de Ley de Transparencia y acceso a la información pública y el margen de actuación de las Comunidades Autónomas", Revista Andaluza de Administración Pública, núm. 84, 2012, pp. 89-134; BARRERO RODRÍGUEZ, C., "La disposición adicional $1.3^{\circ}$ del Proyecto de Ley de Transparencia, acceso a la información y buen gobierno y sus negativos efectos en el ámbito de aplicación del derecho de acceso a la información", Revista Española de Derecho Administrativo, núm. 158, 2013, pp. 221-246; FERNÁNDEZ RAMOS, S., "El acceso a la información en el Proyecto de Ley de Transparencia, acceso a la información y buen gobierno", Revista Aragonesa de Administración Pública, 2013, pp. 233-298.

9 Sobre el tema, véase GUICHOT, E., "El sentido, el contexto y la tramitación de la Ley de transparencia, acceso a la información pública y buen gobierno", en GUICHOT. E. (coord.), Transparencia, Acceso a la Información Pública y Buen Gobierno. Estudio de la Ley 19/2013, de 9 de diciembre, Ed. Tecnos, Madrid, 2014, pp. 17-34.

${ }^{10}$ Así, y en respuesta a la consulta pública formulada por el Gobierno al aprobar el Anteproyecto de Ley, que se desarrolló entre los días 26 de marzo a 10 de abril 2012, la página web creada al efecto recibió 78.107 visitas, 3.669 observaciones por vía telemática y 14 por registro. Se trató de un "buzón ciego" en que no podían conocerse las observaciones de los demás ciudadanos, que nunca se publicaron, ni los participantes recibían respuesta. No había, pues, interactuación. Al ser requerido el Gobierno por el Grupo parlamentario socialista para que le diera traslado de los resultados de la consulta, alegó la pretendida imposibilidad derivada del derecho a la protección de datos de los participantes (en realidad, debía entenderse que ¡el que participa en una consulta pública para la elaboración de una ley da su consentimiento implícito para el manejo de la información por sus representantes parlamentarios precisamente para la finalidad de la tramitación de la ley! Además, podrían haberse facilitado anonimizadas. Es un ejemplo (más) de perversión en el manejo de la normativa sobre protección de datos. No obstante facilitó un resumen de las principales cuestiones planteadas, en que destacaban las propuestas de ampliación de los sujetos obligados, de reconocimiento del derecho de acceso a la información como un derecho fundamental, de eliminación del silencio negativo y de creación de un órgano verdaderamente independiente de control.

11 De acuerdo con el llamado Barómetro de la Transparencia en España 2015, elaborado por Consultores CSA para Acreditra, para el 92,9\% de los encuestados la transparencia es importante o muy importante y para el 71,5\% puede ayudar a prevenir la corrupción. El 71,9\% sabe que existe una Ley de Transparencia y el 79,8\& la valora positivamente o muy positivamente. El 65,2\% afirma conocer a qué obliga transparencia en la gestión pública y el 53,9\% conoce la existencia del Portal de Transparencia, al que el $76,3 \%$ valora positiva o muy positivamente, afirmando haberlo visitado el 7,9\%. 
expectativas depositadas por la sociedad en esta norma como instrumento de regeneración democrática ${ }^{12}$.

Si bien el paso de la inmovilidad al sprint por la transparencia, en una suerte de búsqueda de una relegitimación por parte de los políticos, tiene algo de sonrojante, mirado en positivo, es un buen ejemplo de cómo se puede contribuir desde abajo, desde la sociedad, a fijar las prioridades políticas y a mover a la acción a los grupos parlamentarios y al Gobierno en pos, en este caso, de un objetivo, la transparencia, que, de suyo, tiende a provocar la cautela cuando no el vértigo en la mente de los legisladores y de los administradores, incluso de aquellos que están convencidos, en el plano teórico, de sus evidentes y contrastadas bondades.

Finalmente, de todo ello salió una norma plenamente homologable con la de los países de nuestro entorno, que tiene carácter básico y es de aplicación a un amplio espectro de sujetos obligados ${ }^{13}$. En efecto, las Comunidades Autónomas y las Entidades Locales estuvieron al margen del proceso de elaboración de la LT pero están llamadas a desarrollarla y aplicarla, pues sus instituciones y sujetos vinculados a ellas figuran entre los obligados en los mismos términos que sus equivalentes de ámbito estatal, como veremos. La LT ha hecho un entendimiento muy amplio de la competencia para establecer las bases del régimen jurídico de las Administraciones públicas, de modo que casi toda la regulación tiene carácter básico, incluidas las disposiciones sobre procedimiento. El ámbito propio que ha quedado para las leyes autonómicas está en la ampliación de las materias sujetas a publicidad activa y la determinación de los medios para llevarla a cabo, en las disposiciones de organización y en las medidas para garantizar la eficacia del derecho (formación del personal, elaboración de guías ciudadanas, etc.) y en la creación de autoridades independientes de transparencia o la atribución de sus competencias a autoridades independientes ya existentes. Junto a

${ }^{12} \mathrm{Su}$ disposición final séptima de la LT prevé su entrada en vigor al año de su publicación, en el ámbito estatal (esto es, el 10 de diciembre de 2014), mientras que los órganos de las Comunidades Autónomas y Entidades Locales disponen de un plazo máximo de dos años para adaptarse a sus obligaciones (es decir, según la interpretación mayoritaria que refiere el dies a quo a la publicación de la LT, el 10 de diciembre de 2015).

${ }_{13}$ El ámbito subjetivo es amplio, y combina los criterios orgánico, funcional y de financiación. En efecto, comprende de una parte a todo el sector público y a las instituciones constitucionales y estatutarias o colegios profesionales o cámaras, en relación con sus actividades sujetas al Derecho administrativo. También a las personas físicas y jurídicas privadas que presten servicios públicos o ejerzan funciones administrativas, que están obligadas a suministrar a la entidad pública a las que se encuentren vinculadas la información que les sea solicitada para cumplir con las obligaciones previstas en la Ley, previo requerimiento. O, finalmente, a partidos políticos, sindicatos, organizaciones de empresarios, y a las entidades privadas que reciben financiación pública a partir de un determinado porcentaje o cuantía (a los que la Ley andaluza ha sumado los centros concertados en los términos del concierto y los prestadores de servicios públicos locales en gestión indirecta en los términos que fijen las ordenanzas que regulen el servicio público y los pliegos). 
ello, cabe plantear que el plazo, establecido en un mes con carácter básico, puede ser acortado. No puede decirse lo mismo respecto de las limitaciones o del sentido del silencio, que constituyen una pieza clave en la delimitación del alcance del derecho y sus relaciones con otros bienes públicos y privados en concurrencia ${ }^{14}$.

El retraso en la aprobación de la LT hizo que diversas Comunidades Autónomas tomaran la delantera, aprobando sus propias leyes sobre la materia ${ }^{15}$. Otras se aprobaron con posterioridad ${ }^{16}$. En casi todas las demás estaban en marcha iniciativas en diversos parlamentos autonómicos que decayeron con las elecciones de 2015 y que sin duda se retomarán y los Gobiernos de otras Comunidades Autónomas están elaborando proyectos de leyes.

Estas iniciativas autonómicas dejan aún un margen de autonomía a las entidades locales que, básicamente, pueden ampliar aún más las materias objeto de publicidad activa, deben diseñar sus portales de transparencia y tomar decisiones en cuanto a la organización interna que permita llevar a efecto las determinaciones en materia de transparencia, y, si quieren, acortar más aún el plazo de respuesta a las solicitudes de acceso a la información ${ }^{17}$. Y, de este modo, nos encontramos ahora con toda una batería de aprobación de Ordenanzas locales sobre transparencia.

${ }_{14}$ Sobre la extensión de las bases estatales y el margen de actuación de las leyes autonómicas, véase GUICHOT, E., "El Proyecto de Ley de transparencia y acceso a la información pública y el margen de actuación de las Comunidades Autónomas", op. cit. Ya aprobada la Ley en GUICHOT, E., "Transparencia: aspectos generales", en GUICHOT, E. (coord.), Transparencia..., op. cit., pp. 47-50.

${ }^{15}$ Es el caso de la Ley 4/2006, de 30 de julio, de transparencia y buenas prácticas en la Administración pública gallega (ya derogada), de la Ley Foral 11/2012, de 21 de junio, de Transparencia y del Gobierno Abierto de Navarra o de la Ley 4/2013, de 21 de mayo, de Gobierno Abierto de Extremadura.

${ }^{16}$ La primera de ellas la Ley 1/2014, de 24 de junio, de Transparencia Pública de Andalucía. Le ha seguido la Ley 3/2014, de 11 de septiembre, de Transparencia y Buen Gobierno de la Rioja, la Ley 12/2014, de 16 de diciembre, de Transparencia y Participación Ciudadana de la Región de Murcia, la Ley 12/2014, de 26 de diciembre, de Transparencia y Acceso a la Información Pública de Canaria, la Ley 19/2014, de 29 de diciembre, de Transparencia, Acceso a la Información Pública y Buen Gobierno de Cataluña, la Ley 3/2015, de 4 de marzo, de Transparencia y Participación Ciudadana de Castilla y León, Ley 8/2015, de 25 de marzo, de Transparencia de la actividad pública y Participación ciudadana de Aragón, la Ley 2/2015, de 2 de abril, de Transparencia, Buen gobierno y Participación Ciudadana de Comunidad Valenciana, y la Ley 1/2016, de 18 de enero, de Transparencia y Buen Gobierno, que deroga la Ley de 2006.

${ }^{17} \mathrm{Al}$ respecto, hay que destacar que la Junta de Gobierno de la Federación Española de Municipios y Provincias, FEMP, aprobó el 27 de mayo de 2014 una Ordenanza Tipo de transparencia, acceso a la información y reutilización que, basada en buena medida en experiencias pioneras de algunos municipios, ofrece un modelo que puede inspirar a las ordenanzas locales que pueda aprobar cada entidad, si bien en parte cubierto por las leyes autonómicas que han establecido un trenzado de obligaciones de transparencia muy extenso en publicidad activa y recortado plazos de publicidad pasiva, haciendo que la Ordenanza suponga, en fin, una aportación adicional muy relativa. 
En definitiva, mi segunda hipótesis es que la transparencia ha sido una prioridad fijada de abajo arriba al calor de casos de corrupción que han producido una desconfianza radical en la política y en las instituciones.

\section{TERGERA HIPÓTESIS: LA LEY ESPAÑOLA Y LA MAYOR PARTE DE LAS LEYES AUTONÓMICAS SE SITÚAN EN UN RANGO RAZONABLE DE EXIGENGIA, PERO DEJA UN AMPLIO MARGEN DE DESARROLLO NORMATIVO Y DE INTERPRETAGIÓN APLICATIVA DE GUYO USO DEPEN- DERÁ EL NIVEL REAL DE TRANSPARENCIA}

La normativa sobre transparencia, estatal y autonómica y local, suscita toda una serie de cuestiones que es imposible abarcar en un trabajo de reducidas dimensiones como el presente. El detalle de la regulación lo he estudiado en otros trabajos, a los que me remito ${ }^{18}$. Ahora sólo quería destacar que, con carácter general, acoge un estándar razonable de exigencia en cada uno de sus aspectos, pero deja un amplio margen al aplicador. Será el análisis del desarrollo normativo y la interpretación y la aplicación de la normativa el que nos dé la medida real de la transparencia de la actuación pública.

Así, por ejemplo:

\section{- Limites.}

La LT ha optado por establecer un listado exhaustivo de bienes y derechos cuya posible afectación en caso de concederse el acceso puede limitar el derecho ${ }^{19}$. Ahora bien, hay que advertir que, al no haberse dotado a la LT del carácter de orgánica, y teniendo en cuenta que no existe en nuestro sistema jurídico una ordenación jerárquica o por troncalidad entre leyes ordinarias, jurídicamente bien podría el legislador estatal, por disruptivo que fuera, añadir nuevos límites por leyes singulares. No cabe decir lo mismo de las leyes autonómicas o de los reglamentos locales, por cuanto estamos

\footnotetext{
${ }^{18}$ Véase, por todos, E. GUICHOT (coord..), Transparencia, ..., op. cit.

${ }^{19}$ En su art. 14 se fijan los siguientes: a) La seguridad nacional. b) La defensa. c) Las relaciones exteriores. d) La seguridad pública. e) La prevención, investigación y sanción de los ilícitos penales, administrativos o disciplinarios. f) La igualdad de las partes en los procesos judiciales y la tutela judicial efectiva. g) Las funciones administrativas de vigilancia, inspección y control. h) Los intereses económicos y comerciales. i) La política económica y monetaria. j) El secreto profesional y la propiedad intelectual e industrial. k) La garantía de la confidencialidad o el secreto requerido en procesos de toma de decisión. l) La protección del medio ambiente. El listado del artículo 14 se complementa con un artículo posterior, el 15, dedicado al derecho a la intimidad y la protección de datos.
} 
ante un precepto con carácter básico ${ }^{20}$. En cuanto a la interpretación y ponderación de los límites, el carácter abstracto de su formulación es indiscutible, pero, en mi opinión, no había alternativa razonable, pues la realidad es tan proteica que el intento de una definición en positivo resulta un esfuerzo vano abocado al fracaso. Se trata de un campo abonado para la permanente y gradual tarea de perfilar la ponderación a que en cada particular supuesto haya de llegarse a ejercer por los sujetos obligados, en primer término, por la autoridad independiente de control, en segundo y destacado lugar, y por los tribunales, que tienen la última palabra. La práctica de décadas en el Derecho comparado no ofrece lugar a dudas en este sentido. La doctrina que se vaya fijando en su aplicación contribuirá a ofrecer un vademécum o guía de orientación al aplicador, y de la mayor o menor "generosidad" en la interpretación va a depender en una evidente medida el mayor o menor nivel de transparencia real. La LT contiene evidentes indicaciones que abonan una interpretación restrictiva de los límites. En efecto, su aplicación se contempla con carácter relativo ("el derecho de acceso podrá ser restringido"), puesto que está sometida al test del perjuicio ("cuando la divulgación de la información suponga un perjuicio para"). Está sujeta además a un principio de maximización del derecho, que lleva a que las restricciones tengan el mínimo alcance necesario ("la aplicación de los límites será justificada y proporcionada a su objeto y finalidad de la protección"), lo que conecta con el principio de acceso parcial, acogido en el artículo 16, conforme al cual en los casos en que la aplicación de alguno de los límites no afecte a la totalidad de la información se concederá el acceso parcial previa omisión de la información afectada por el límite salvo que de ello resulte una información distorsionada o que carezca de sentido, en cuyo caso, deberá indicarse al solicitante qué parte de la información ha sido omitida. Resulta discutible la posibilidad excepcional de no conceder acceso alguno en los casos en que la omisión dé lugar a información distorsionada o carente de sentido, que puede dar lugar a abusos en su interpretación por algunos aplicadores, en lugar de que sean los propios destinatarios los que juzguen la utilidad de la información concedida, por lo que podría haber sido más conveniente, a mi juicio, la redacción propuesta por diversas enmiendas, como vimos, suprimiendo esta posibilidad y previendo acaso una advertencia en estos casos de la distorsión o falta de sentido que a juicio del aplicador puede implicar el acceso parcial concedido. Además, la LT permite que incluso en los casos en que el acceso suponga un perjuicio para los bienes en cuestión pueda prevalecer el interés público o privado en conocer la información si éste es juzgado "superior". Aparece aquí como clave de bóveda el principio de ponderación, que es la espita que permite en el caso concreto valorar la importancia que para la sociedad tiene conocer la información en

${ }^{20}$ Sin embargo, la Ley catalana ha suprimido algunos de ellos, lo que nos parece contrario a las bases estatales (recuérdese que eliminar límites no es, o no es sólo, ampliar el derecho de los ciudadanos, sino que también supone recortar los derechos de los ciudadanos afectados en su intimidad, en sus intereses económicos, o garantías de bienes públicos colectivos que les afectan). 
cuestión, incluso si con ello se causa un perjuicio para uno de sus bienes ${ }^{21}$. Pese a todas estas prevenciones, como puede observarse, una aplicación de "mala fe" casi siempre será capaz de encontrar asidero (o excusa) en algunos de los límites tan numerosos y abstractos. Por ello, sólo la práctica en la aplicación de los límites nos dará la medida de la transparencia.

\section{- Publicidad activa.}

La LT establece el principio general de publicación activa de la información "cuyo conocimiento sea relevante para garantizar la transparencia de su actividad relacionada con el funcionamiento y control de la actuación pública", con aplicación de los límites antes estudiados. Además, se prevé que se dé publicidad a la información que se solicite con mayor frecuencia. A ello se le une, y es algo que valoro de forma muy positiva, la inclusión de un catálogo de toda una serie de información sumamente relevante, clasificada en "institucional, organizativa y de planificación", la información "de relevancia jurídica", y la información "económica, presupuestaria y estadística" (sobre proyectos normativos, planes y su evaluación, presupuestos y su ejecución, contratos convenios, subvenciones, que incluye esta última nada más y nada menos todos los contratos, convenios y subvenciones, sin excepción y con detalles sobre el procedimiento seguido para su adjudicación u otorgamiento, contenido, modificaciones, currículos, retribuciones e indemnizaciones de altos cargos, patrimonio público inmobiliario, etc.). Hay aquí un gran campo para la ampliación por vía de la legislación autonómica y de los reglamentos locales, que está siendo en efecto colmado ${ }^{22}$. La

${ }^{21}$ Sin embargo, la LT alude a la posibilidad de que prevalga un interés público "o privado", el del solicitante concreto de información. Como señalé en mi comparecencia en la Comisión Constitucional del Congreso, pugnando por su corrección, esta previsión, contraria a principios bien asentados en el Derecho supranacional y comparado, supone un grave desconocimiento del fundamento del derecho de acceso, que no es un derecho instrumental al servicio de la protección de otros derechos, sino un derecho autónomo al servicio de la transparencia, la participación y el control de la actuación pública, conectado con el Estado democrático y, por ende, al margen de cualquier distinción en función de la motivación que pueda tener el solicitante (que, por ello mismo, no exige). Dicho de otro modo, el único parámetro con el que confrontar la protección de los límites es el valor que para la sociedad tiene el conocimiento de la información, un juicio abstracto desvinculado por completo de la cualidad y motivación del solicitante. Lo que, por lo demás, hace que una vez concedido el acceso, la información pueda circular libremente en la sociedad y ser conocida por cualquiera (de hecho, diversos sistemas prevén la publicación automática de la información una vez entregada a uno o varios solicitantes). La previsión, es contradictoria con la falta de exigencia de ningún interés y, por ende de motivación, con el propio sentido del derecho de acceso y perturba, pues, de forma grave el entero sistema y pone en cuestión su acomodación al CEADP en general al Derecho comparado. Dicho de otra manera, en materia de transparencia, el peso del interés en la divulgación de información es el mismo, ya pida la información Agamenón o su porquero.

${ }_{22}$ La Ley andaluza, por ejemplo, ha ampliado la publicidad activa a las agendas institucionales de los gobiernos, relaciones de puestos de trabajo, catálogos de puestos o equivalentes, referidos a todo tipo de personal "con indicación de sus retribuciones anuales", inventario de entes, información sobre 
publicación ha de hacerse en las correspondientes "sedes electrónicas o páginas web". $\mathrm{Al}$ respecto, se están poniendo en marcha los llamados portales de transparencia. Se prevé la publicación "de forma periódica y actualizada", si bien la ley estatal y la mayor parte de normas autonómicas no prevén plazos concretos de publicación y de mantenimiento de la información publicada. Ahora bien, la práctica de los portales desvela, hasta el momento, prácticas discutibles o directamente contrarias a esta regulación, como la falta de publicación de determinados contratos menores, la publicación de las resoluciones de compatibilidad de empleados públicos, sin identificación de las personas beneficiarias, etc.

\section{Publicidad pasiva}

La otra cara de la publicidad activa es la publicidad pasiva o "derecho de acceso a la información pública", mecanismo no limitado ya a categorías de información, como la publicidad activa, sino general. El plazo de resolución acogido como básico en la LT se mueve dentro de parámetros comparados razonables: un máximo de un mes desde la recepción por el órgano competente para resolver, ampliable por otro mes en el caso de que el volumen o la complejidad de la información que se solicita así lo hagan necesario, previa notificación al solicitante ${ }^{23}$. No obstante, en uso de sus competencias, los sujetos obligados pueden reducir (que no ampliar, al ser una garantía básica) normativamente dicho plazo. El sentido del silencio, negativo en la LT, tiene carácter básico. Por ello ni las leyes autonómicas ni los reglamentos locales podrían tampoco cambiar esta regla por esta misma razón, pues ha de tenerse en cuenta que el silencio positivo, al margen de la complejidad de su efectividad en una materia como ésta que requiere de la puesta a disposición de información, supondría la puesta en peligro de otros bienes constitucionales públicos y privados protegidos por los límites establecidos en la propia $\mathrm{LT}^{24}$. Ahora bien, resulta evidente que la efectividad del derecho de los ciudadanos dependerá en buena medida de que los sujetos obligados respondan de hecho en plazo y en que no se escuden en respuestas que nieguen la propia existencia de la información ${ }^{25}$. En todo caso, en mi opinión, un aspecto crucial

financiación y deuda pública, orden del día de reuniones gobiernos y acuerdos con información contenida en el expediente.

${ }^{23}$ En su criterio interpretativo núm. 5, de 14 de octubre de 2015, el Consejo de Transparencia estatal ha recalcado que la ampliación debe ser notificada al solicitante antes del plazo de un mes de forma motivada.

${ }^{24}$ Sin embargo, algunas leyes autonómicas han establecido un sui generis silencio positivo, salvo que una norma con rango de ley prevea lo contrario $(s i c)$. Es el caso de las leyes navarra, catalana (que añade que en todo caso "no se puede adquirir por silencio administrativo el derecho de acceso si concurre alguno de los límites establecidos por esta u otras leyes para tener acceso a la información pública.”), aragonesa y valenciana.

${ }^{25}$ La LT prevé que frente a la desestimación expresa o presunta cabe interponer una reclamación ante 
es la interpretación que se dé a las causas de inadmisión previstas en la LT y reproducidas con algunas precisiones en la legislación autonómica. Conviene prestarles la debida atención porque en su interpretación se juega no poco de la efectividad del derecho de acceso, y se trata en todos los casos de conceptos muy vagos, como los de información "en curso de elaboración o de publicación general"26, "información que tenga carácter auxiliar o de apoyo como la contenida en notas, borradores, opiniones, resúmenes, comunicaciones e informes internos o entre órganos o entidades administrativas"27; "información para cuya divulgación sea necesaria una acción de previa reelaboración"28; "solicitudes dirigidas a un órgano en cuyo poder no obre la

la autoridad independiente de control en el plazo de un mes. El Consejo de Transparencia estatal ha interpretado en su criterio interpretativo núm. 10 de 17 de febrero de 2016 que en los casos de desestimación presunta no hay plazo para reclamar, alineándose así con la jurisprudencia constitucional y con las normas sobre procedimiento administrativo.

${ }^{26}$ Trata de salvaguardar una cierta economía de medios y eficacia de la gestión de la información. Podría haberse precisado la obligación de informar al solicitante del órgano responsable, el plazo previsto de terminación y el modo de publicación, como han precisado numerosas leyes autonómicas. La Ley andaluza precisa que la denegación de información deberá especificar el órgano que elabora dicha información y el tiempo previsto para su conclusión y puesta a disposición.

${ }^{27}$ Esta causa de inadmisión contiene un criterio general y una serie de ejemplificaciones. El criterio general de exclusión de la "información de carácter auxiliar o de apoyo", por lo demás, no definida en Derecho, parece razonable; sin embargo, la mención en la ejemplificación de los informes internos ha sido criticada, en la medida en que, por su ambigüedad, puede dar lugar a abusos. La Ley andaluza dispone que los informes preceptivos no podrán ser considerados como información de carácter auxiliar o de apoyo, en sintonía con la enmienda 471 que presentara en su día en el Congreso de los Diputados el Grupo parlamentario socialista), ni aquellos que son externos (incluidos dictámenes, informes solicitados a peritos, etc.), a salvo, claro está, de que concurra alguno de los límites legales, pero no ya como causa de exclusión, esto es, como impedimento ab initio, sino tras un juicio ponderado. El Consejo de Transparencia estatal, en su criterio interpretativo núm. 6, de 12 de noviembre de 2015, ha interpretado que esta causa de inadmisión ha de interpretarse restrictivamente y hay que estar al carácter de la información, y no a su formato o denominación, y ha puesto como ejemplos de información auxiliar la que contiene opiniones valoraciones personales del autor que no manifiesten la voluntad del órgano o institución, cuando se trate de un texto preliminar o borrador sin la consideración de final, cuando se trate de información preparatoria de la actividad del órgano o entidad, cuando se trate de comunicaciones internas que no constituyan trámites del procedimiento o cuando se trate de informes no preceptivos y que no sean incorporados a la motivación de una decisión final.

${ }^{28} \mathrm{Al}$ apoyarse sobre el concepto "información" y no de "documento", el legislador español se ha visto necesitado de establecer alguna restricción ante la posibilidad de solicitudes genéricas que conviertan a los sujetos obligados en auténticos "consultores" al servicio de cualquier solicitante, y al respecto dispone que se exceptúan del derecho de acceso la información para cuya divulgación "sea necesaria una acción previa de reelaboración", concepto éste cuya interpretación más o menos amplia va a ser uno de los elementos nucleares de la aplicación de la Ley. Parece que hay que estar a un criterio de razonabilidad. Es decir, por una parte, no se debería entender que la "reelaboración" implica que si la información solicitada no coincide exactamente con la contenida en un documento individual determinado debe inadmitirse la solicitud. Si ése hubiera sido el resultado querido, la LT se habría apoyado en el concepto de documento. Una interpretación tal frustraría radicalmente las expectativas puestas en la Ley. La práctica revela cómo la información solicitada lo es a menudo en forma de preguntas directas sobre datos, que pueden requerir a menudo la "confección" de la respuesta; máxime cuando estamos ya en un mundo digital en que la información figura 
información cuando se desconozca el competente"29; o "solicitudes que sean manifiestamente repetitivas o tengan un carácter abusivo no justificado con la finalidad de transparencia" 30 .

\section{Sanciones}

La LT es muy parca en lo que se refiere al régimen sancionador por el incumplimiento de sus previsiones. Tan sólo, y ante las críticas que suscitó durante la tramitación pre-parlamentaria y parlamentaria la ausencia de previsión de sanciones,

en bases de datos a menudo interconectadas. Pero, por otra parte, claro está que, si se opta, como ha hecho la LT, por un concepto tan amplio como el de "información", en lugar del más común de "documento", es necesario establecer alguna restricción ante la posibilidad de solicitudes genéricas que conviertan a los sujetos obligados en auténticos "consultores" al servicio de cualquier solicitante, que revelen un uso abusivo con cargo a fondos públicos y con capacidad de paralizar el funcionamiento de los servicios administrativos. Sólo la práctica y las resoluciones de las autoridades de control y de los tribunales irán afinando -y sólo en lo posible- el entendimiento de este concepto, que sin duda va a ser controvertido. El debate se ha planteado a nivel mundial, singularmente en la reforma de la normativa sobre acceso a los documentos de la Unión Europea, sugiriéndose que se abra el acceso a los datos que sin figurar en documentos singularizados, puedan obtenerse de bases de datos mediante procedimientos sencillos, solución ésta acogida en la normativa autonómica. La Ley de Andalucía precisó que no puede considerarse como reelaboración la información que pueda obtenerse mediante un tratamiento informatizado de uso corriente. El Consejo de Transparencia estatal, en su criterio interpretativo núm. 7 de 12 de noviembre de 2015, ha determinado que en estos casos la decisión de inadmisión a trámite habrá de ser motivada en relación con el caso concreto y hará expresión de las causas materiales y los elementos jurídicos en los que se sustenta; que la reelaboración supone un nuevo tratamiento de la información y no debe confundirse con otros supuestos tales como el volumen o la complejidad de la información solicitada, la inclusión de datos personales susceptibles de anominización o el acceso parcial de la información, supuestos que no son causas de inadmisión; y, finalmente, que las dificultades en la reelaboración han de basarse en elementos objetivables de carácter organizativo, funcional o presupuestario, que deben ser expresados en resolución motivada.

${ }^{29}$ Esta causa de inadmisión hay que relacionarla con otros preceptos. El artículo 17.1, que prevé que la solicitud se dirija al titular del órgano que posea la información; el apartado segundo del propio artículo 18, conforme al cual en el caso de que se inadmita una solicitud por concurrir esta causa, el órgano que acuerde la inadmisión deberá indicar en la resolución el órgano que, a su juicio, es competente para conocer de la solicitud; y el 19.1, según el cual si la solicitud se refiere a información que no obre en poder del sujeto al que se dirige, ésta la remitirá al competente, si lo conociera, e informará de esta circunstancia al solicitante. El conjunto de estas disposiciones denota una innegable incoherencia, en su tal vez bien intencionado intento de apurar al máximo el auxilio al solicitante a la hora de localizar al órgano que posee la información, que es ciertamente necesario en un sistema tan complejo de competencias como el nuestro.

${ }^{30} \mathrm{El}$ rechazo a las solicitudes manifiestamente abusivas es una previsión ampliamente generalizada en el Derecho comparado. No es necesario puntualizar que la apreciación de esta causa de inadmisión ha de ser claramente restrictiva por lo que es saludable la precisión de que en todo caso ha de ser aplicada siempre en relación con la finalidad de transparencia, que, en depende qué casos, puede justificar solicitudes poco espaciadas en el tiempo tratándose de asuntos en permanente actualización, o bien referidas a un volumen considerable de información, cuando se relaciona toda ella con un mismo tema. De nuevo habrá que estar para mayores concreciones a los criterios que respecto de cada tipo de información vayan sentando las autoridades de control y la jurisprudencia. 
castiga como infracción grave a los efectos de la normativa de régimen disciplinario los incumplimientos reiterados de las obligaciones de publicidad activa o de la obligación de resolver en plazo las solicitudes de acceso. Se trata de una laguna sumamente llamativa. Esta parquedad da pie a un amplio desarrollo por las leyes autonómicas, que, respetando lo establecido con carácter básico, establezca un completo catálogo de infracciones y sanciones tanto por autoridades como por empleados públicos y entidades privadas sujetas a las obligaciones de transparencia ${ }^{31}$. Ahora bien, aún en estos casos se plantean importantes incógnitas, como por ejemplo quién sería el competente para sancionar a un Presidente de Comunidad Autónoma o a un Alcalde o presidente de Diputación o si se trata de un puro brindis al sol, y, si es así, cómo se cohonesta con la previsión contenida en la normativa autonómica - entre ellas, la andaluza- según la cual Autoridad independiente, cuando constate incumplimientos susceptibles de ser calificados como alguna de las infracciones antes referidas, instará la incoación del procedimiento y el órgano competente está obligado a incoar el procedimiento y a comunicar a la Autoridad independiente las medidas.

En suma, mi tercera hipótesis es que, ante una normativa que se apoya en los conceptos jurídicos indeterminados y en la ponderación, la medida de la transparencia vendrá en buena medida de la mano no sólo de la regulación legal sino de su interpretación y aplicación por los operadores jurídicos.

\section{CUARTA HIPÓTESIS: SIN AUTORIDADES DE GONTROL INDEPENDIENTES DE DERECHO Y DE HECHO NO HA- BRÁ AUTÉNTICA TRANSPARENGIA}

Conectemos ahora las tres hipótesis iniciales para llegar a una cuarta y última: si la normativa sobre transparencia ha sido aprobada como exigencia y reacción ciudadana ante el descrédito de la política y no basta si no va acompañada de mecanismos que garanticen una interpretación no restrictiva de la que dependen el nivel real de transparencia, podemos fácilmente concluir que sin autoridades de control independientes de derecho y de hecho no habrá auténtica transparencia. Y es que en materia de información, o se garantiza una respuesta independiente, rápida y gratuita a los reclamantes, o la tutela del derecho de acceso a la información no es efectiva.

El Derecho comparado muestra como es la solución mayoritaria y cómo el papel de estas autoridades al interpretar y resolver es decisivo en la efectividad del derecho de acceso.

31 Véase al respecto la completa y contundente regulación contenida en el Título VI de la Ley de Transparencia Pública de Andalucía (arts. 50 a 58). 
Ciertamente, la LT prevé que frente a toda resolución cabe recurso ante la jurisdicción contencioso-administrativo (cualquiera que sea la naturaleza de Derecho público o privado de su autor, obsérvese). Pero también prevé como garantía básica la posibilidad de interponer una reclamación previa ante una autoridad independiente. Debe recalcarse que se tratan de reclamaciones que sustituyen a los recursos administrativos y están dotadas por ello de plena fuerza ejecutiva y ejecutoria, es decir, son vinculantes y de obligado cumplimiento, a expensas de la posibilidad de impugnación ante los tribunales contencioso-administrativos, como vimos, y del efecto suspensivo de este eventual recurso sobre su eficacia.

Para el ámbito estatal, la LT regula una autoridad administrativa independiente de nueva creación, el Consejo de Transparencia y Buen Gobierno. Su Presidente es nombrado por el Gobierno y ratificado por el Congreso de los diputados por mayoría absoluta. Su mandato no renovable es de cinco años y sus causas de cese son tasadas. Concentra las principales funciones ejecutivas, entre ellas, las de resolver las reclamaciones. Junto al este órgano unipersonal ejecutivo se encuentra la Comisión, órgano colegiado e interinstitucional, con competencias que podríamos calificar de menores ${ }^{32}$.

La disposición adicional cuarta de la LT dispone, desde su versión inicial, que la resolución de la reclamación corresponde, en los supuestos de resoluciones dictadas por las Administraciones de las Comunidades Autónomas y su sector público, y por las Entidades Locales comprendidas en su ámbito territorial, "al órgano independiente que determinen las Comunidades Autónomas". Optativamente, permite a las Comunidades Autónomas y a las Ciudades Autónomas atribuir la resolución de las reclamaciones al CTBG, siempre que celebren el correspondiente convenio con la AGE, en el que se estipulen las condiciones en que la Comunidad sufragará los gastos derivados de esta asunción de competencias. Algunas de ellas se han acogido a esta posibilidad ${ }^{33}$. Obsérvese que, en el caso de las Entidades Locales, la LTBG también opta, aparentemente, por una solución similar a la contenida en la LOPD, la de atribuir la competencia a un órgano independiente autonómico ${ }^{34}$.

${ }^{32}$ Se optó por este modelo y no por otro que integrara también a representantes de la sociedad civil (consumidores y usuarios, ONGs, expertos...), lo que podría haber sido una buena idea, como habían demandado algunos expertos.

${ }^{33}$ Han suscrito convenio al tiempo de redactar estas líneas Asturias, Cantabria, Castilla-la Mancha, La Rioja, Extremadura y Ceuta.

${ }^{34}$ Curiosamente, la Ley murciana restringe la competencia de su Consejo al ámbito autonómico y deja en el limbo a las entidades locales. 
Dejando al margen a las Comunidades que han optado por suscribir convenio con el Consejo estatal y aquellas otras que no se han adaptado aún a esta obligación básica, los modelos adoptados han sido heterogéneos.

Las más optan por instituciones de nueva creación dedicadas sólo a la transparencia, con múltiples variantes: órgano colegiado de extracción parlamentaria $(\mathrm{Ca}-$ taluña) o integrado por representantes de instituciones estatutarias (Aragón), órgano unipersonal de extracción parlamentaria (Canarias); órgano colegiado con poderes ejecutivos elegido por el Parlamento y órgano colegiado consultivo con representantes de Instituciones públicas y sociales (Valencia). Andalucía ha optado por atribuir a una misma Institución de nueva creación la competencia en materia de transparencia y protección de datos, en la que las competencias ejecutivas las concentra el Presidente, de elección parlamentaria, y la Comisión, que integra a representantes institucionales $\mathrm{y}$ sociales tiene funciones meramente consultivas ${ }^{35}$. El modelo mayoritario ha sido el de elección parlamentaria por mayoría reforzada, mandato no renovable y causas de cese tasadas.

Otras Comunidades han residenciado la competencia para la resolución de reclamaciones en el Defensor del Pueblo autonómico (Castilla-León y Galicia) - mutando así para esta materia la hasta ahora "consustancial" naturaleza no ejectutiva de sus resoluciones.

A mi juicio, la clave para enjuiciar la mayor o menor adecuación de estas fórmulas organizativas no es otra que la garantía de cualificación y de independencia. Elecciones por mayoría cualificada, causas de cese tasadas y mandatos no renovables parecen pautas normativas adecuadas. En cuanto a la cualificación, no se ha avanzado más allá en su caso de la exigencia de una serie de años de experiencia en materia relacionada, de forma más o menos cercana, con la materia. Habría sido conveniente un sistema de concurso y audiencias, como se propone en el modelo interamericano.

${ }^{35}$ Lo que, como he defendido en otros trabajos, me parece la solución idónea a nivel autonómico, en el que el principal límite a la primera es la segunda y es necesario soluciones que armonicen ambos derechos y resuelvan los conflictos a que pueda darse lugar de forma homogénea, en pro de la seguridad jurídica. Sobre las ventajas e inconvenientes de la unificación de competencias en una misma autoridad en los ámbitos estatal y autonómico, y favorable a ello en el autonómico, me pronuncié ya en Transparencia y Acceso a la Información en España: análisis y propuestas legislativas, Fundación Alternativas, Madrid, 2011, y posteriormente en El Proyecto de Ley de Transparencia..., op. cit., p. X. 
En todo caso, y es mi cuarta y última hipótesis, es esencial que la cualificación y la independencia no se queden en el papel sino que marquen la práctica. Que los titulares de estas Instituciones estén realmente cualificados y realmente actúen con independencia. Sin ello la ley nacerá muerta y no servirá ni política ni jurídicamente ${ }^{36}$.

${ }^{36} \mathrm{Al}$ frente del Consejo de Transparencia estatal el Gobierno del Partido Popular nombró en noviembre de 2014, con la ratificación del Congreso de los Diputados en el que contaba con mayoría absoluta, a su primera Presidenta, María Esther Arizmendi Gutiérrez, licenciada en Derecho y Técnico Superior de Administración Civil del Estado y de Administración Local, tras cesar el mes anterior como Directora general de Modernización Administrativa. Procedimientos e Impulso de la Administración Electrónica del Ministerio de Hacienda y Administraciones Públicas. Pese a las prevenciones que podía generar el que hubiera ostentado un alto cargo justo hasta el nombramiento o su previsible retorno a la alta función pública tras la expiración de su mandato donde de ser nombrada para otro puesto, la ejecutoria hasta el momento muestra que el porcentaje de estimaciones parece razonable y que comienza a darse conflictividad judicial en casos en que los sujetos obligados a dar información discrepan de las decisiones del Consejo, cuya defensa en juicio corresponderá a abogados contratados a tal fin, y no a la Abogacía del Estado, para evitar conflictos de intereses en la defensa jurídica, lo que parece imprescindible. En el ámbito autonómico, los perfiles de las personas nombradas son muy diversos, no siempre juristas ni personas con especial cualificación en la materia. Aún es pronto para valorar su ejecutoria. 